[Agr. Biol. Chem., Vol. 30, No. 5, p. 452 456, 1966]

\title{
Studies on Nitrogen Metabolism in Tobacco Plants
}

\author{
Part VII. A $^{\mathrm{N}}$-Pyrroline-5-carboxylate Reductase \\ from Tobacco Leaves \\ By Masao Noguchi, Akira KoIwaI and Einosuke TAMaKI \\ Central Research Institute, Japan Monopoly Corporation \\ Nishi-Shinagazea, Shinagawa-ku, Tokyo, Japan \\ Received November 10, 1965
}

\begin{abstract}
41-Pyrroline-5-carboxylate reductase has been considerably purified from tobacco leaves. This enzyme uses NADPH or NADH for the formation of proline, although the former is better used. This enzyme was found in washed chloroplast extract as well as in cytoplasmic fluid and utilized NADPH, formed by the photosynthetic NADP reduction, for the sythesis of proline in the light.
\end{abstract}

As previously reported, ${ }^{11}$ the biosynthesis of proline from glutamate in tobacco leaves is highly active in the daytime whereas it proceeds very slowly at night, although the oxidation of proline to glutamate takes place at a comparatively slow rate in the daytime and at night without any appreciable difference. These results suggested that light might play an important role in the biosynthesis of proline from glutamate in green leaves, possibly by means of photoreduction and photophosphorylation.

Although proline has been shown to be synthesized in various microorganisms from glutamate through glutamic- $\gamma$-semialdehyde and its cyclization product, $\Delta^{1}$-pyrroline-5carboxylate, ${ }^{2,3)}$ no study is yet available on the enzymes of this pathway in higher plants. In order to elucidate the role of light in the biogenesis of proline in green leaves, these enzyme systems in tobacco leaves have been investigated and this paper describes the occurrence of $\Delta^{1}$-pyrroline-5-carboxylate reductase in tobacco chloroplasts and a possible role of light in this reaction.

1) S. Mizusaki, M. Noguchi and E. Tamaki, Arch. Biochem. Biophys., 105, 599 (1964).

2) H.J. Vogel and B. D. Davis, J. Am. Chem. Soc., 74 109 (1952). 3) H. J. Vogel and D. M. Bonner, Proc. Natl. Acad. Sci.,
40, 688 (1954).

\section{EXPERIMENTAL}

Broken Chloroplasts and Chloroplast Extract. Broken chloroplasts and chloroplast extract were prepared according to the method of Whatley, Allen and Arnon ${ }^{4}$ for spinach chloroplasts with slight modification. Plants of Nicotiana tabacum, "Bright Yellow", were grown in a green house and young expanded leaves were harvested usually in the morning prior to each experiment. After the leaves had been washed with distilled water, midribs were removed from the leaves and discarded.

Leaf blades $(25 \mathrm{~g})$ were sliced into pieces and ground by hand in a precooled mortar with $50 \mathrm{ml}$ of $0.35 \mathrm{~m} \mathrm{NaCl}$ solution which contained both sodium ascorbate and mercaptoethanol at a concentration of $0.01 \mathrm{M}, 5 \mathrm{ml}$ of $0.5 \mathrm{M}$ Tris- $\mathrm{HCl}$ buffer $\mathrm{pH} 8.0$, and about $10 \mathrm{~g}$ of silica sand. The slurry was squeezed through four layers of cheesecloth, and the filtrate was centrifuged for 1 minute at $200 \mathrm{~g}$. The supernatant fluid was further centrifuged for 7 minutes at $1,000 \mathrm{~g}$, and the resultant sediment was suspended in $25 \mathrm{ml}$ of washing medium consisting of $0.35 \mathrm{M} \mathrm{NaCl}$, $0.01 \mathrm{M}$ sodium ascorbate, and $0.01 \mathrm{M}$ mercaptoethanol. The suspension was centrifuged for 7 minutes at $1,000 \mathrm{~g}$, and the green sediment (washed chloroplasts) was carefully resuspended in $5 \mathrm{ml}$ of ice-cold hypotonic solution consisting of $0.035 \mathrm{M} \mathrm{NaCl}, 0.01 \mathrm{M}$ sodium ascorbate, and $0.01 \mathrm{~m}$ mercaptoethanol. The suspension was centrifuged for 10 minutes at $18,000 \mathrm{~g}$. The supernatant liquid was used as chloroplast ex4) F. R. Whatley. M. B. Allen and D. I. Arnon, Biochim. Bioplyys. Acta, 32, 32 (1959). 
tract. The lower layer of the sediment consisted of strach grains which were brought out by the disruption of chloroplasts. The green upper layer was resuspended in $5 \mathrm{ml}$. of the hypotonic solution described above and used as broken chloroplasts. All these procedures were carried out at $0 \sim 4^{\circ} \mathrm{C}$.

Tobacco Ferredoxin.

Tobacco ferredoxin was extracted and purified from young tobacco leaves according to the method of Tagawa and Arnon for spinach ferredoxin,5) omitting the last step for the crystallization. Specific activity of the ferredoxin preparation was 38.9 units per $\mathrm{mg}$ protein, according to the definition by San Pietro and Lang.6)

\section{Reactions under Illumination.}

Photosynthetic reactions with chloroplast fragments were carried out aerobically in $50 \mathrm{ml}$ Erlenmeyer flasks with a flat bottom. The flasks were immersed in a glass water bath kept at $20^{\circ} \mathrm{C}$ and illuminated from the bottom by a bank of 150-watt tungsten bulbs, approximately 20,000 lux at the level of the reaction flasks. The reaction was started by turning on the light and terminated after one hour by turning off the light and adding $0.3 \mathrm{ml}$ of $2 \mathrm{~N} \mathrm{HCl}$. The acidified reaction mixtures were heated in a boiling water bath for 1 minute, cooled immediately, and centrifuged. The whole supernatant liquid was concentrated in vacuo to dryness, and subjected to the assay of proline.

Assay of the Enzyme Activity.

Optical assay of the enzyme activity was carried out as follows. Ten micromoles of $\mathrm{DL}-\Delta^{1}$-pyrroline- 5-carboxylate, 0.4 micromole of NADPH and enzyme were incubated at $25^{\circ} \mathrm{C}$ in $0.025 \mathrm{M}$ phosphate buffer, $\mathrm{pH} 7.0$, in a total volume of $3.0 \mathrm{ml}$. The decrease in absorbancy at $340 \mathrm{~m} \mu$ for the initial 3 minutes was followed and correction was made for the endogenous oxidation of NADPH. An enzyme unit is defined, according to Peisach and Strecker, 7 as the enzyme amount which produces a decrease in optical density of 0.001 per minute at $340 \mathrm{~m} \mu(1.0 \mathrm{~cm}$ light path).

\section{Reagents and Analytical Procedures.}

DL- $\Delta$-Pyrroline-5-carboxylate was prepared by the method of Strecker et al.7,8) and neutralized with $\mathrm{Na}_{2} \mathrm{CO}_{3}$ before use. Chlorophyll was estimated by the method of Amon') and protein by the method of Lowry et al.10) Proline was determined with a Beckman/Spinco Amino Acid Analyzer. NADP, NADPH and NADH were obtained from Boehringer \& Soene GmbH, Mannheim, Germany.

\section{RESULTS AND DISCUSSION}

Distribution of $A^{1}$-Pyrroline-5-Carboxylate Reductase in Tobacco Leaves.

Enzymic reduction of $A^{1}$-pyrroline-5-carboxylate (hereafter abbreviated to PCA) by various cell fractions of tobacco leaves are listed in Table I with glutamic acid decarboxylase activity of each fraction.

As shown in the table, the specific activity of PCA reduction with the chloroplast extract was similar to that with the supernatant. On

\section{Table I. Reduction of PCA and Decarboxylation of Glutamate by Cell fractions}

\section{Cell fraction}

$200 \sim 1,000 \mathrm{~g}$ (washed chloroplasts)

$1,000 \sim 18,000 \mathrm{~g}$ (grana and mitochondria)

$18,000 \mathrm{~g}$ supernatant

chloroplast extract

\section{$\mu$ mole proline produced ? per $\mathrm{mg}$ protein per $\mathrm{hr}$.}
0.288
0.236
1.25
1.68

umole glutamate decarboxylated ${ }^{b}$ per $\mathrm{mg}$ protein per hr.

a) The reaction mixture contained in a total volume of $2 \mathrm{ml}, 2 \sim 10 \mathrm{mg}$ prote in of each fraction, $100 \mu \mathrm{moles}$ of phosphate buffer, pH $7.0,5 \mu$ moles of NADPH and 10 moles of DL-PCA. Reactions were carried out for $30 \mathrm{~min}$. at $30^{\circ} \mathrm{C}$ in the dark. Control experiments were carried out without NADPH.

Control experiments were carried out without NADPH. b) The glutamic acid decarboxylase was assayed by measuring the radioactity Tri.Carb Flow Monitor System. The U-C14-glutamic acid using a Beckman/Spinco Amino Acid Analyzer and a Packard Tri.Carb Fos phote buffer, pH 5.7, and reaction mixture contained in a total volume of $2 \mathrm{ml}, 0.3$ to $0.9 \mathrm{mg}$ protein, $100 \mu \mathrm{moles}$.

$10 \mu$ moles $(1 \mu \mathrm{C})$ of U-C $14-$ glutamic acid. Reactions were carried out for $30 \mathrm{~min}$. at $30^{\circ} \mathrm{C}$.

5) K. Tagawa and D.I. Arnon, "Modern Method of Plant Analysis," Vol. VII, Springer-Verlag, 1964, p. 595.

6) A. San Pietro and H.M. Lang, J. Biol. Chem., 231, 211 (1958).

7) J. Peisach and H. J. Strecker, J. Biol. Chem., 237, 2255 (1962).
8) H. J. Strecker, J. Biol. Chem., 235, 2045 (1960)

9) D.I. Arnon, Plant Physiol., 24, 1 (1949).

10) O. H. Lowry, N. J. Rosebrough, A.L. Farr and R.J. Randall, J. Biol. Chem., 193, 265 (1951). 
the other hand, glutamic acid decarboxylase activity in the supernatant is much higher than that in the chloroplast extract. As these results suggested that PCA reductase might be concerned with chloroplasts as well as with cytoplasm, chloroplast extracts were used as crude enzyme in this study.

\section{PCA Reduction with Chloroplast Extract in the Dark.}

Table II shows that PGA is reduced to proline in the dark with chloroplast extract in the presence of NADPH or NADH as a hydrogen donor. Both NADH and NADPH have been reported to serve as hydrogen donors for PCA reduction, although the activity with NADPH is much higer than that with NADH in Neurospora, ${ }^{11}$ whereas the reverse trend is observed with mammalian liver. ${ }^{7,121}$

TABLE II. REDUCTION OF PCi WITH Chloroplast Extract

Expt. A

Content of proline ( $\mu$ mole)

complete

complete minus NADPH

2.40

complete minus PCA

0.10

0.11

complete minus chloroplast extract

0.13

Expt. B

Hydrogen donor

NADPH

$\mathrm{NADH}$

2.78

none

2.32

0.04

Complete reaction mixture contained in a tatal volume of $3 \mathrm{ml} ; 1 \mathrm{ml}$ of chloroplast extract, $80 \mu$ moles of Tris buffer $\mathrm{pH} 7.5,10 \mu$ moles of DL-PCA, and $5 \mu$ moles of reduced pyri dine nucleotide. In Expt. A, NADPH was used as the hydrogen donor. Reactions were carried out for 1 hour at $30^{\circ} \mathrm{C}$ and stopped by adding $0.3 \mathrm{ml}$ of $\mathrm{N}$ hydrochloric acid into the mixture.

In the case of chloroplast extract, NADPH seems to be a little better utilized than NADH although the difference is less significant than that in the purified enzyme described below.

11) T. Yura and H. J. Vogel, J. Biol. Chcm., 234, 335 (1959).

12) M.E. Smith and D. M. Greenberg, ibid., 226, 317 (1957).
Purification of PCA Reductase in Tobacco Leaves.

Since PCA reductase in higher plants has not yet been studied, partial purification of this enzyme from tobacco leaves was undertaken.

Young expanded tobacco leaves $(1 \mathrm{~kg})$, freed from midribs and freezed in a deep-freezer, were macerated with 31 of $0.1 \mathrm{~m}$ phosphate buffer, $\mathrm{pH} 7.5$, which contained sodium ascorbate $(0.01 \mathrm{M})$, and EDTA $(0.002 \mathrm{M})$, in a Waring blendor for 5 miuntes. The homogenate was filtered through four layers of cheesecloth and the residue was discarded. The filtrate was centrifuged at $2,500 \mathrm{~g}$ for 15 minutes and the sediment was discarded. To the supernatant fluid was added a calculated amount of powdered ammonium sulfate to give $25 \%$ saturation; $\mathrm{pH}$ of the fluid was maintained between 7 to 7.5 with aqueous ammonia during the addition procedure. The precipitate thus obtained was removed by centrifugation at $16,000 \mathrm{~g}$ for 5 minutes and discarded. The supernatant solution was further brought to $50 \%$ saturation with ammonium sulfate and the resulting precipitate, which had the majority of the enzyme activity, was collected by centrifugation and dissolved in $300 \mathrm{ml}$ of $0.05 \mathrm{M}$ phosphate buffer, $\mathrm{pH} 7.0$, containing $0.005 \mathrm{~m}$ mercaptoethanol and $0.001 \mathrm{M} \mathrm{EDTA}^{*}$ (Fraction A).

Fraction A was again fractionated with ammonium sulfate and the precipitate obtained between 30 and $45 \%$ saturation was dissolved in $150 \mathrm{ml}$ of the phosphate buffer (Fraction B). Fraction B was further treated with ammonium sulfate, and the precipitate obtained from 35 to $45 \%$ saturation was dissolved in $10 \mathrm{ml}$ of the phosphate buffer (Fraction C). Fraction $\mathrm{C}$ was then passed through a column of Sephadex G-200 $(3 \mathrm{~cm} \times$ $25 \mathrm{~cm}$ ) equilibrated with the same phosphate buffer. The main PCA reductase fraction (Fraction D) thus obtained was fractionated

\footnotetext{
* This buffer solution was used to dissolve the enzyme throughout the purification procedure.
} 
Table III. Summary of Purification Procedures

\section{Fraction}

Crude supernatant fluid

Fraction A (Ammonium sulfate I)

Fraction B (Ammonium sulfate II)

Fraction C (Ammonium sulfate III)

Fraction D (Sephadex treatment I)

Fraction E (Ammonium sulfate IV)

Fraction $\mathbf{F}$ (Sephadex treatment II)

Fraction $G$ (Ammonium sulfate $V$ )

Total units
555,000
792,000
606,000
508,000
462,000
325,000
145,000
138,000

As for the assay procedure, see the text.

with ammonium sulfate at 45 to $50 \%$ saturation and the fraction was dissolved in $10 \mathrm{ml}$ of the phosphate buffer (Fraction E). Fraction $E$ was passed through a Sephadex $G-200$ column $(3 \times 25 \mathrm{~cm})$ and the fractions which had high PCA reductase activity were collected (Fraction F). Fraction $F$ was finally fractionated with ammonium sulfate, at 45 to $50 \%$ saturation and the precipitate obtained was dissolved in $10 \mathrm{ml}$ of the phosphate buffer (Fraction G). All steps in the purification were carried out at 0 to $4^{\circ} \mathrm{C}$.

A summary of the yields and purifications obtained at each step in the preparation of the enzyme is presented in Table III.

Treatment of the enzyme preparation with protamine sulfate, or chromatography with a DEAE-cellulose column resulted in a large loss of activity, although the purity of the enzyme was doubled by the latter procedure.

The enzyme is relatively stable in the solution with mercaptoethanol and can be stored at room temperature for a few days or at $4^{\circ} \mathrm{C}$ for more than 2 weeks with little or no loss in activity.

pH Optimum and Pyridine Nucleotide Specificity.

As shown in Fig. 1, the optimum $\mathrm{pH}$ for the enzyme action was observed around 7.0, either with NADH or NADPH as the hydrogen donor. However, the activity with NADPH was relatively higher than that with $\mathrm{NADH}$ within the tested $\mathrm{pH}$ range.

$\begin{array}{ccc}\begin{array}{c}\text { Total protein } \\ (\mathrm{mg})\end{array} & \begin{array}{c}\text { Specific activity } \\ \text { units/mg protein }\end{array} & \begin{array}{c}\text { Yield } \\ (\%)\end{array} \\ 41,700 & 13.3 & 100 \\ 12,700 & 62.4 & 143 \\ 2,640 & 230 & 109 \\ 1,500 & 338 & 91.5 \\ 1,130 & 409 & 83.2 \\ 511 & 636 & 58.6 \\ 134 & 1,080 & 26.1 \\ 65.7 & 2,100 & 24.9\end{array}$

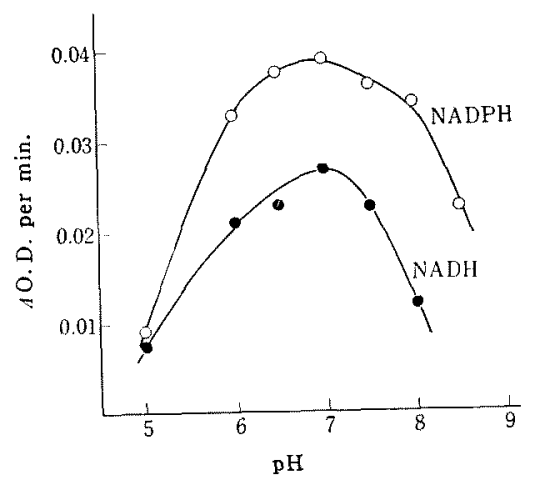

FIG. 1. $\mathrm{pH}$ Dependence and Pyridine Nucleotide Specificity of the Enzyme.

Assay procedures were as given in the text.

TABle IV. INhibitors OF PCA Reductase of TOBACCO LEAVES

$\begin{array}{lcc}\text { Component } & \begin{array}{c}\text { Concentration } \\ (\mathrm{M})\end{array} & \begin{array}{c}\text { Inhibition } \\ (\%)\end{array} \\ \text { ATP } & 1.0 \times 10^{-3} & 46 \\ & 3.3 \times 10^{-3} & 63 \\ \text { ADP } & 1.0 \times 10^{-3} & 14 \\ & 3.3 \times 10^{-3} & 46 \\ \text { NADP } & 1.7 \times 10^{-3} & 54 \\ \text { NAD } & 1.7 \times 10^{-3} & 15 \\ \text { L-proline } & 1.0 \times 10^{-3} & 0 \\ & 1.0 \times 10^{-2} & 8 \\ \text { Mgt+ } & 3.3 \times 10^{-3} & 0 \\ \text { Ag } & 1.7 \times 10^{-4} & 52 \\ \text { NH+ } & 1.0 \times 10^{-2} & 7 \\ \text { p-chloromercuribenzoate } & 1.0 \times 10^{-3} & 25\end{array}$

Enzyme used was from the last step in purification, at the concentration of $4.3 \mu \mathrm{g}$ per ml. Assay procedure was the same as described in the text. 


\section{Inhibitors.}

PCA reductase in tobacco leaves seems to be an $\mathrm{SH}$ enzyme as the enzyme from other sources, ${ }^{7,11,12)}$ for it is inhibited by $\mathrm{Ag}^{+}$and $p$-chloromercuribenzoate as seen in Table IV The enzyme is also inhibited by ATP, ADP, NAD and NADP. Proline does not inhibit the enzyme even in the concentration of $10^{-2} \mathrm{M}$, although some authors ${ }^{7,13)}$ have reported that proline inhibits the enzyme in relatively high concentrations.

Reduction of PCA to Proline with Chloroplasts under Illumination.

As mentioned above, the biosynthesis of proline in tobacco leaves is greatly enhanced in the light. This enhancement seems to be operative either in the step of the reduction of glutamate to PCA or in that of PCA to proline, or in both steps. In PCA reduction, which requires NADPH as a hydrogen donor, the effect of light on the reaction seems to be in the photoreduction of NADP to NADPH. In order to confirm this assumption, reduction of PCA to proline with NADP and chloroplasts under illumination was carried out. As

\footnotetext{
13) E. Adams and A. Goldstone, J. Biol. Chem., 235, 3499
} $(1960)$.
TABLE V. PCA REDUCTION UNDER ILLUMINATION

\begin{tabular}{lc}
\multicolumn{1}{c}{ Treatment } & $\begin{array}{c}\text { Proline Content } \\
(\mu \text { mole })\end{array}$ \\
light, complete & 2.24 \\
light, minus chloroplast extract & 0.18 \\
light, minus PCA & 0.11 \\
light, minus NADP & 0.10 \\
dark, complete & 0.19
\end{tabular}

The complete mixture contained, in a final volume of $3 \mathrm{ml}$; chloroplast extract, $1.5 \mathrm{ml}$ (equivalent to $2.8 \mathrm{mg}$ chlorophyll), broken chloroplasts containing $0.48 \mathrm{mg}$ of chlorophyll, 3 units of purified tobacco ferredoxin, and the followings in $\mu$ moles: Tris. pH 7.5, $80 ; \mathrm{MgCl}_{2}, 5 ; \mathrm{MnCl}_{2}, 2$; NADP, 1 ; DL.PCA, 10. As for the other reaction conditions, see the text.

shown in Table V, proline was produced from PCA with chloroplast extract and NADP in the presence of broken chloroplasts and tobacco ferredoxin under illumination.

Thus, as far as the reduction of PGA is concerned, a role of light in the biosynthesis of proline seems only to reduce NADP to NADPH with the non-cyclic electron flow system in photosynthesis.

Acknowledgement. The authors wish to thank Miss Kyoko Yamamoto and Mr. Kenji Saito for their technical assistance. 